\title{
Variation for Grain Morphology, Molecular Diversity and Aroma Analysis in Specialty Rice of Assam
}

\author{
Deepmoni Hazarika and Sharmila Dutta Deka
}

National Seed Project, Department of Plant Breeding and Genetics, Assam Agricultural University, Jorhat

\section{Article history:}

Received: 20 July, 2021

Revised: 02 Aug., 2021

Accepted: 18 Aug., 2021

\section{Citation:}

Hazarika D and SD Deka. 2021. Variation for Grain Morphology, Molecular Diversity and Aroma Analysis in Specialty Rice of Assam. Journal of Cereal Research 13 (Spl1): 84-91. http://doi.org/10.25174/25822675/2021/115273

\section{*Corresponding author:}

E-mail: sharmila9368@gmail.com

\begin{abstract}
The nature and magnitude of genetic diversity of aromatic rice accessions collected from different agro climatic zones of Assam were evaluated in the present study. Grain morphology and molecular diversity was investigated for a collection of fourteen genotypes. In molecular genetic analysis 32 random SSR markers and 1 gene- based marker (Aroma-1) were included, out of which 18 informative SSR were employed for genetic analysis on the basis of their amplification. Molecular taxonomy and genetic divergence analysis revealed considerable variation among the tested aromatic lines. Of the 18 SSR variation in 14 genotypes, the value of PIC ranged from 0.1326 (RM337) to 0.5408 (RM496). The phylogenetic relations indicate presence of diverse genetic origin of the aromatic rice collection. Aroma analysis with gene based marker (Aroma- 1) amplified a unique band in Bokul Joha which is different from rest of the genotypes indicating probable presence of alternative allelic constitution of BADH2 gene for aroma.
\end{abstract}

Keywords: Aroma analysis, aromatic rice, grain morphology, molecular diversity, phylogenic relationship

\section{Introduction}

Aromatic rice is a specialty rice group that possesses aroma, has been cultivated mostly in South and SouthEast Asian countries from ancient times and is highly prized in the world market and tied to folk customs (Itani et al., 1983). Grain aroma is one of the key characteristic of quality rice whose importance is realized not only in Asian market but also widely recognized in Europe and other parts of the World (Wakte et al., 2017). More than 100 volatile compounds have been identified in rice (Dudareva et al., 2013; Mathure et al., 2011; Mathure et al., 2014.). Among these compounds 2-acetyl-1-pyrroline (2-AP) is identified as the principal aroma compound. The level of aroma expression generally associated with the increased levels of 2-acetyl-1-pyrroline (2AP) (Buttery et al., 1983; Widjaja et al., 1996; Yoshihashi, 2002). In order to assist in the rapid development of fragrant rice varieties suited to particular environmental conditions, rice breeders need a simple and inexpensive method for identification of fragrant rice genotypes. Chemical methods are available which involve smelling leaf tissue or grains after heating in water or reacting with solutions of $\mathrm{KOH}$ or I2-KI (Sood et al., 1978) but these can not quantify the aroma. An objective method of 2AP identification using gas chromatography is available but the assay requires large tissue samples and is time consuming (Lorieux et al., 1996). PCR-based DNA markers were developed to generate polymorphisms that can distinguish aromatic from non aromatic genotypes. Molecular markers closely linked to the aroma gene or " $f g r$ " QTL can be used to facilitate early selection for the presence of aroma. Researcher defined the chromosomal location of the gene by mapping in segregating populations using simple sequence repeat (SSR) or microsatellite and single nucleotide polymorphism (SNP) markers (Cordeiro et al., 2002; Jin 
et al., 2010). A recessive gene, on chromosome 8 of rice, largely controlling the level of 2-acetyl-1-pyroline, has been identified in genetic studies (Bradbury et al., 2005). Based on positional cloning, the major aroma gene was identified as a defective or non-functional allele of the gene coding betaine aldehyde dehydrogenase (BADH2 gene) with an 8 base pair deletion and 3 SNPs observed in Exon 7 generating a pre-mature stop codon to the $B A D H 2 \mathrm{mRNA}$, resulting in its loss of function and accumulation of 2-AP is responsible for aroma (Bradbury et al., 2005).

Breeding rice varieties with preferred grain quality features has become second most important objective next to yield. Therefore, assessment of diversity of available germplasm is important pre-breeding exercise. There are reports on wide variability for pheno-genomic traits including grain quality characters and its importance in aromatic rice breeding programmes (Islam et al., 2018). India is home to wide varieties of rice cultivars, landraces and many lesser known varieties. The landraces maintained by farmers are endowed with tremendous genetic variability and valuable genes for unique aroma (Prodhan et al., 2020). Varietal diversity in indigenous rice is found to suit varying growing conditions, ethnic preferences and diverse uses (Mo et al., 2015; Thakur et al., 2020).Rice diversity is also well explained using molecular markers(Dwivedi $e t$ al., 2019; Kaur et al., 2020) The present study is formulated looking at future prospects and demand of the aromatic rice breeding projects. Understanding the dynamics of expression pattern of $B A D H 2$ gene in different aromatic rice varieties grown in different parts of Assam will help in characterization of trait of aroma in the cultivated aromatic rice of Assam. This study also describes nature and extent of genetic variation in aromatic rice collected from six different agro-climatic regions of Assam in regards to grain quality. Further a simple PCR based method targeting the candidate gene for fragrance, will be amenable for routine genetic purity testing of aromatic rice collection.

\section{Materials and Methods}

\subsection{Experimental materials}

Experimental material consists of 14 native aromatic rice germplasms including traditional and improved varieties (Table 1) collected from different agro climatic regions of Assam. The pre-germinated seeds were sown in the field following randomized block design with three replications in July, 2018 in the Instructional cum Research farm of Assam Agricultural University.

Table 1. Rice varieties with accession numbers

\begin{tabular}{cc}
\hline S. No. & Genotypes \\
\hline 1 & Badshah bhog $(J 2)$ \\
2 & Bhoboli joha $(J 4)$ \\
3 & Boga joha $(J 6)$ \\
4 & Maniki madhuri joha $(J 10)$ \\
5 & Boga tulsi $(J 11)$ \\
6 & Borshal joha $(J 12)$ \\
7 & Chuban joha $(J 14)$ \\
8 & Gualporiya joha-1 $(J 15)$ \\
9 & Joha bora $(J 19)$ \\
10 & Kon joha-2 $(J 22)$ \\
11 & Kola joha-1 $(J 24)$ \\
12 & Kaljira $(J 29)$ \\
13 & Keteki joha $(K J)$ \\
14 & Bokul joha $(B J)$ \\
\hline
\end{tabular}

\subsection{Grain characteristics}

The grain morphology was studied with five taxonomic traits along with grain Amylose content. Ten competitive plants were randomly selected from each genotype in each replication to record the data following test guidelines for the conduct of test for Distinctiveness, Uniformity and Stability for rice (2007).

\subsection{Molecular characterization}

The genomic DNA was extracted from young seedlings following CTAB method developed by Murray and Thompson (1980) with slight modification.A total of 32 SSR primers were used in the present study and the informative primers are listed in the Table 2. PCR was performed in $20 \mathrm{\mu l}$ reaction volumes containing $25 \mathrm{ng}$ of DNA, 50 pmol each forward and reverse primer for SSR, $25 \mu \mathrm{M}$ of dNTPs (Fermentas, Bangalore Genei) and 0.6 $\mathrm{U}$ of Taq Polymerase (Bangalore Genei). PCR program was followed as, initial denaturation at $94{ }^{\circ} \mathrm{C}$ for $3 \mathrm{~min}$ followed by 35 cycles, each consisting of denaturation at $94{ }^{\circ} \mathrm{C}$ for $1 \mathrm{~min}$, annealing at appropriate temperature for $1 \mathrm{~min}$ and elongation at $72{ }^{\circ} \mathrm{C}$ for $2 \mathrm{~min}$ for SSR primers. A final extension step included $72^{\circ} \mathrm{C}$ incubation for $7 \mathrm{~min}$ followed by hold at $4{ }^{\circ} \mathrm{C}$. Perkin Elmer (model 9600) thermo-cycler was used to carry out the reaction. 
The amplified DNA fragments were resolved on ethidium bromide stained agarose gel $(2.5 \%)$ in $1 \mathrm{X}$ TAE buffer

Table 2. Informative SSR primers with PIC values at $50 \mathrm{~V}$. The gels were visualized on trans-UV and photographed in Bio-red Gel Doc XR 2.0.

\begin{tabular}{|c|c|c|c|}
\hline Marker & Annealing temp. $\left({ }^{\circ} \mathrm{C}\right)$ & Product size (bp) & PIC \\
\hline RM 1 & 55 & $130 \& 110$ & 0.1378 \\
\hline RM 9 & 55 & $180 \& 130$ & 0.1734 \\
\hline RM 10 & 55 & $170 \& 175$ & 0.4688 \\
\hline RM 21 & 55 & $180 \& 140$ & 0.1528 \\
\hline RM 55 & 55 & $230 \& 240$ & 0.4260 \\
\hline RM 164 & 55 & $310 \& 290$ & 0.2602 \\
\hline RM 206 & 55 & $180 \& 140$ & 0.2449 \\
\hline RM307 & 55 & $130 \& 140$ & 0.3368 \\
\hline RM 316 & 55 & $210,200 \& 180$ & 0.4971 \\
\hline RM 336 & 55 & $180 \& 160$ & 0.1860 \\
\hline RM 337 & 55 & $180 \& 150$ & 0.1326 \\
\hline RM 480 & 55 & $220 \& 200$ & 0.3109 \\
\hline RM 496 & 55 & $310,290 \& 270$ & 0.5408 \\
\hline RM 541 & 55 & $190 \& 170$ & 0.3295 \\
\hline RM 548 & 55 & $290 \& 270$ & 0.1357 \\
\hline RM 556 & 55 & $260 \& 240$ & 0.2449 \\
\hline RM 11 & 55 & $130 \& 110$ & 0.1378 \\
\hline RM 12 & 55 & $180 \& 130$ & 0.1734 \\
\hline
\end{tabular}

\subsection{Aroma analysis}

Gene based primers (Table 3) viz., Aroma 1, designed based on the 8 bp deletions and 3 SNPs in the Exon 7 of the defective allele of Betain Aldehyde Dehydrogenase 2 (BADH 2) gene (Bradbury et al., 2005 ) and was used for analysis of aroma among the tested genotypes

Table 3. Aroma 1 primer

\begin{tabular}{cc}
\hline Primer name & Sequence $\left(\mathbf{5}^{\prime}-\mathbf{3}^{\prime}\right)$ \\
\hline External Sense Primer (ESP) & TTGTTGGAGCTTGCTGATG \\
Internal Fragrant Antisense Primer (IFAP) & CATAGGAGCAGCTGAAATATATACC \\
Internal Non-fragrant Sense Primer (INSP) & CTGGTAAAAAGATTATGGCTTCA \\
External Antisense Primer (EAP) & AGTGCTTTACAAGTCCCGC \\
\hline
\end{tabular}

\subsection{Data analysis}

The amplicons were scored as 1 for presence and 0 for absence for each genotype. Polymorphic information content (PIC) was calculated based on bands per primer (Botstein et al., 1980) Cluster analysis was performed using NTSYSpc version 2.1 (Rohlf 1998). Pair-wise combinations of genotypes were employed to calculate Jacquard's similarity coefficient (Jaccard 1908). The similarity matrix was used to generate an "Unweighted Pair Group Method with Arithmetic Average" (UPGMA)based dendrogram (Sneath and Sokal 1973) using the SIMQUAL module of NTSYSpc.

\section{Results and Discussion}

3.1 Genetic variation and comparative performance of genotypes for grain characteristics

The analysis of variance revealed significant differences among the genotypes for all quantitative grain characters under study. The mean performance of genotypes is presented in Table 4. The groupings of the grain characteristics were done following DUS guideline (2007). Based on grain type, genotypes can be classified into three groups. Eight genotypes belongs to long-slender type, four genotypes with long-bold grain and rest three 
are medium-slender type. Pair wise similarity for 14 aromatic rice cultivars based on grain characteristics using euclidean distance coefficient was also calculated. The distance coefficient ranged from 0.713 to 6.890 , indicating no true duplicates. The maximum genetic divergence was observed between Boga joha (J6) and Kaljira (J29), which is 6.890. The lowest diversity (0.713) has been observed between Borshal joha (J12) and Keteki joha. The dendrogram based on grain characteristics, separated the 14 aromatic rice genotypes into two major clusters (Fig. 1). The cluster I with 11 and II consisted of 3 genotype. In the

Table 4: Mean performances of grain characteristics
cluster-I, Borshal Joha and Keteki Joha was indicated as similar varieties. However, there is significant difference for Amylose content and few other grain characters are different among them. Variability in aromatic rice cultivation is reported in many other studies also (Talukdar et al., 2017; Mahajan et al., 2018). The exhibited variability in the present study has immense importance selection of parents for varietal improvement program. The grain morphology data will also help in genetic identification of varieties in maintenance breeding.

\begin{tabular}{|c|c|c|c|c|c|c|}
\hline Genotypes & $\begin{array}{c}\text { Grain } \\
\text { length } \\
(\mathrm{cm})\end{array}$ & $\begin{array}{c}\text { Grain } \\
\text { width } \\
\text { (cm) }\end{array}$ & $\begin{array}{c}\text { Decorticated } \\
\text { grain length } \\
(\mathrm{cm})\end{array}$ & $\begin{array}{c}\text { Decorticated } \\
\text { grain width } \\
(\mathrm{cm})\end{array}$ & $\begin{array}{c}\text { Grain } \\
\mathrm{L} / \mathrm{B} \\
\text { ratio }\end{array}$ & $\begin{array}{c}\text { Amylose } \\
\text { content } \\
(\%)\end{array}$ \\
\hline Badshah Bhog (J2) & 6.00 & 2.17 & 4.25 & 1.50 & 2.46 & 28.70 \\
\hline BhoboliJoha (J4) & 8.25 & 2.00 & 6.33 & 2.00 & 4.34 & 21.30 \\
\hline Boga Joha (J6) & 9.25 & 2.17 & 7.00 & 2.08 & 4.27 & 18.60 \\
\hline Maniki madhuri joha (J 10) & 6.58 & 2.00 & 4.75 & 1.75 & 3.13 & 22.90 \\
\hline Boga Tulshi (J 11) & 6.50 & 2.00 & 4.58 & 2.00 & 3.23 & 24.50 \\
\hline Borshal Joha (J 12) & 8.08 & 2.17 & 6.00 & 2.00 & 3.77 & 19.10 \\
\hline Chuban Joha (J 14) & 6.08 & 2.42 & 4.75 & 2.08 & 2.53 & 18.20 \\
\hline Gualporia Joha -1 (J 15) & 7.33 & 2.00 & 5.83 & 2.00 & 3.65 & 18.00 \\
\hline Joha Bora (J 19) & 7.25 & 3.08 & 5.92 & 2.83 & 2.33 & 12.80 \\
\hline Kon Joha-2 (J 22) & 7.58 & 2.33 & 5.17 & 2.00 & 3.23 & 17.60 \\
\hline Kola Joha-1 (J 24) & 8.58 & 2.83 & 6.08 & 2.50 & 3.03 & 19.70 \\
\hline Kaljira (J 29) & 6.67 & 2.58 & 4.67 & 2.58 & 2.60 & 24.20 \\
\hline KetekiJoha & 8.58 & 2.25 & 6.33 & 2.08 & 3.87 & 24.70 \\
\hline BokulJoha & 5.92 & 2.50 & 4.75 & 2.42 & 2.40 & 22.10 \\
\hline Mean & 7.3333 & 2.3214 & 5.4583 & 2.131 & 3.2038 & 20.8857 \\
\hline S.E. & 0.1418 & 0.1017 & 0.1598 & 0.0674 & 0.1708 & - \\
\hline C.V. & 3.3493 & 7.5871 & 5.0699 & 5.477 & 9.2312 & - \\
\hline C.D. $5 \%$ & 0.4122 & 0.2956 & 0.4644 & 0.1959 & 0.4964 & - \\
\hline
\end{tabular}

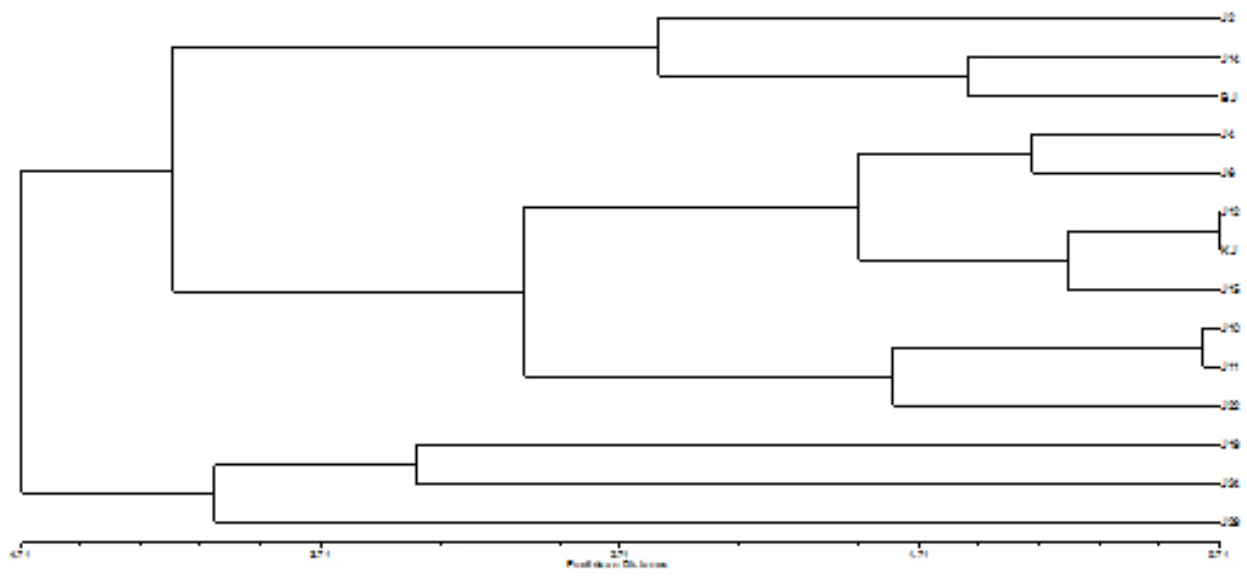

Fig. 1. Dendrogram of rice varieties based on grain morphology 


\subsection{Molecular phylogeny and genetic divergence}

The importance of molecular markers and its application on aromatic rice breeding programmes has been of prime importance for precise and effective breeding programme (Peng et al., 2018). 32 SSR primers were used to study the molecular genetic diversity of the aromatic rice genotypes, out of which 18 primers (Table 2) were polymorphic and were used for genetic analysis. The primers RM496 and RM316 produced three alleles each and the rest have produced two alleles. RM496 had the highest PIC value of 0.5408 and the PIC value was found to be lowest in the marker RM337 (0.1326), indicating RM496 is much more informative in comparison with all the other SSR markers used under study. Allelic variation for few SSR marker is depicted in Fig. 3. The Dendrogram based on UPGMA separated the 14 aromatic rice genotypes into two major clusters (Fig. 2). The cluster I and consisted of 12 genotypes cluster II with 2 genotypes. The majority of genotypes in cluster-I, indicates the close phylogenetic relationship among the cultivated aromatic rice. The clear separation of the two genotypes Bokul Joha and Joha Bora in cluster II from the rest indicates their genetic dissimilarity. The present set of SSR markers could not distinguish between Gualporia joha-1 (J15), Kon joha-2 (J22) and Kola joha-1 (J24) as limited number of SSR markers in the study and their random selection might have amplified the same alleles in all the genotypes warranting the use of more markers to get a better picture of diversity among them. However, the genotypes included in the present study are mostly farmer's varieties and the present result indicates sharing of common parentage among them. Hence, there is a possibility of cultivating the same variety in different names in different locations. Only two varieties in the Cluster II, Joha bora (J19) and Bokul joha, defines similar ancestral origin, hence close phylogenic relationship among them. Short grain aromatic class of rice is locally termed as joha and semi glutinous and glutinous are commonly known as bora in Assam. Local name joha bora indicates the presence of glutinous character in this variety. These 2 genotypes may have ancestral similarities with the glutinous group of rice, some of which have japonica origin .Aromatic rice varieties of NE India represent distinct genetic stock. Global classification places them into both Indica and Japonica types (Jain et al., 2004; Talukdar et al., 2017). Accessions from Assam, Manipur and Sikkim are assigned to indica group, while those from Nagaland exhibit close association with Japonica (Roy et al., 2015). The present study on molecular phylogeny explains the genetic diversity and relationship can be well exploited in future breeding programs.

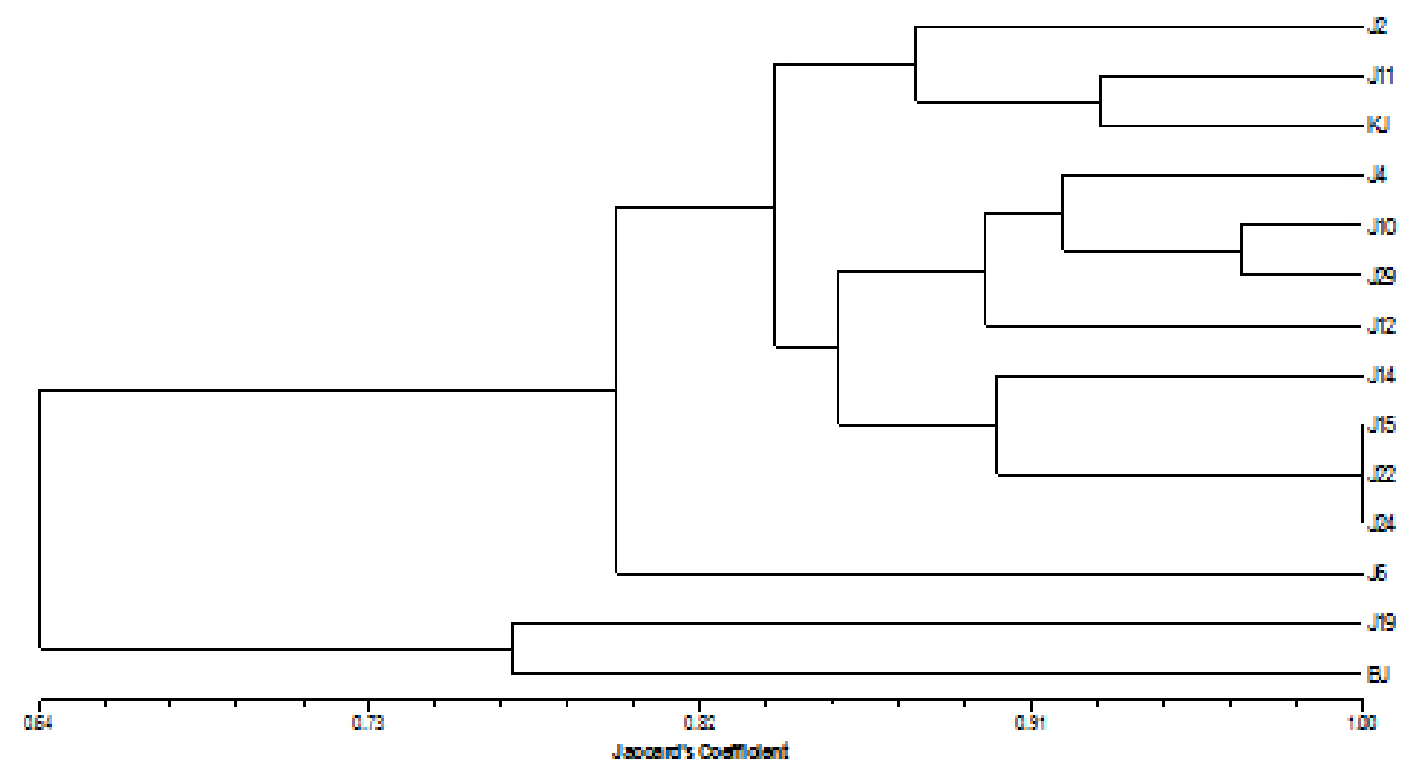

Fig. 2. Dendrogram of rice varieties based on SSR banding pattern 

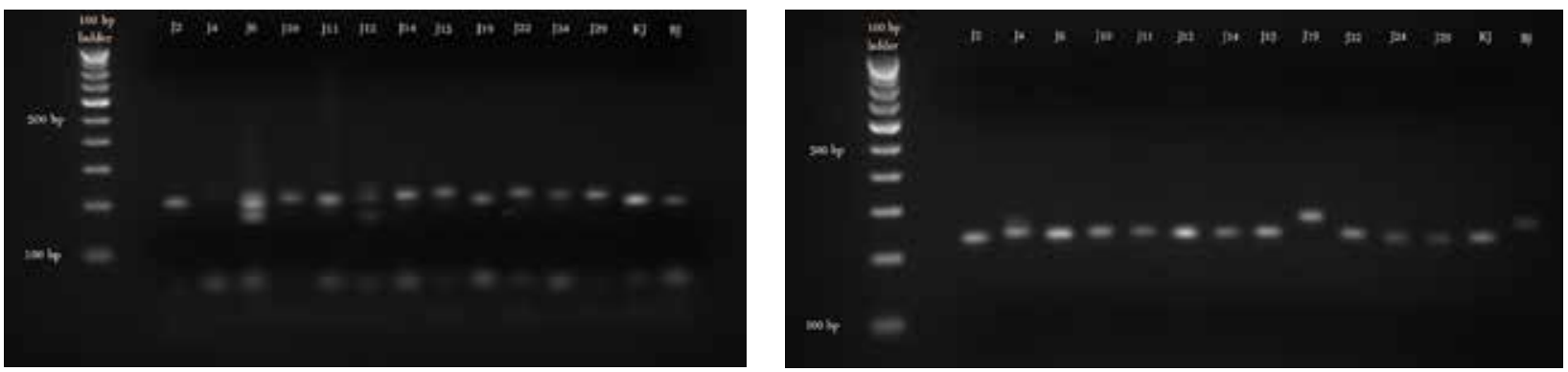

Fig. 3. Polymorphism for SSR RM556 and RM316 among the genotypes

\subsection{Aroma analysis based on gene based primer}

Gene based primer Aroma 1 consists of two external primers viz., ESP and EAP, and two internal primers viz. INSP and IFAP, which is reported to be amplified at a $355 \mathrm{bp}$ band in non-fragrant rice and a band of $258 \mathrm{bp}$ in fragrant rice (Bradbury et al., 2005). All the genotypes revealed the presence of $258 \mathrm{bp}$ band except Bakul Joha and Badshah bhog, confirming the presence of $B A D H-2$ gene for aromatic expression (Fig. 4). A peculiar band produced by Bokul Joha with the primers Aroma 1 is of 355 bp (Fig. 4). This indicates that $B A D H 2$ gene is fully functional and the aroma in Bakul Joha may be due to the presence of additional allele. The genotypes collected from different farmer's field and amplification of aroma allele in Bokul Joha might have due to differential expression in varied environmental condition and due to differential selection pressure. Similar reports have been indicated in several studies about differential expression of aroma in varying environmental conditions. (Pachauri et al., 2014; Hinge et al., 2016). Badshah bhog did not amplify the aroma allele implying the absence of $B A D H 2$. However the name of the variety Badshah bhog indicates its ancestral origin may not from local aromatic rice although it contains other grain characters similar to local Joha type. The present study implies, apart from Badshah bhog (J2) and Bokul joha, the aroma in rest of the cultivars among the tested genotypes, may be due to defective BADH 2 allele which is similar to the earlier reports (Bradbury et al., 2005; Yi et al., 2009; Fitzgerald et al., 2010; Talukdar et al., 2017).

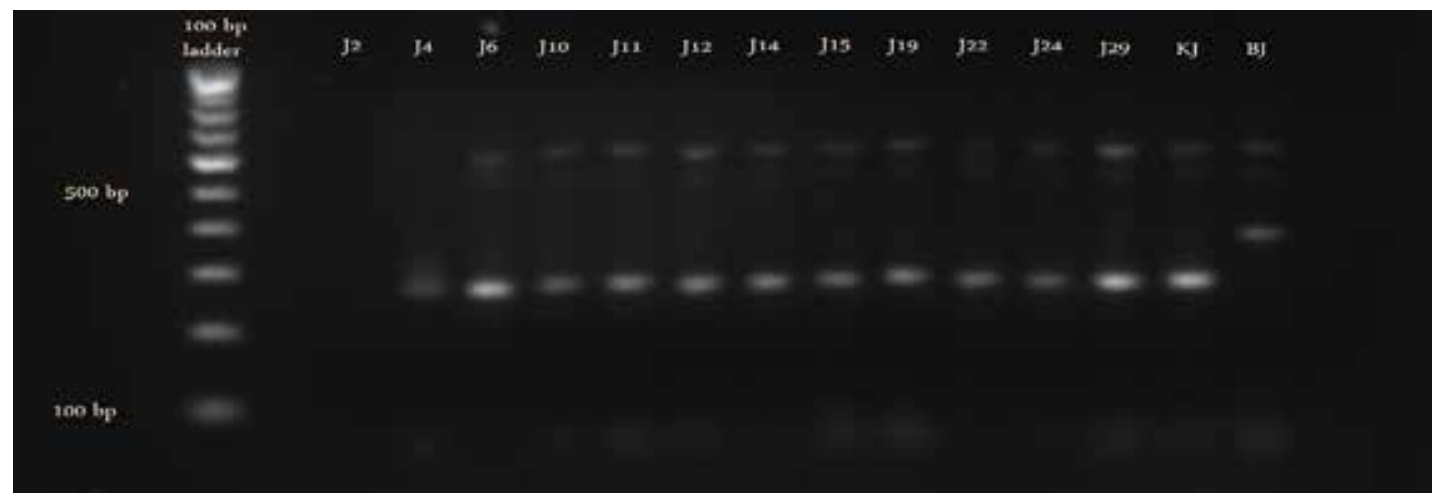

Fig. 4. Aroma analysis: allelic distribution of Marker Aroma 1 (ESP + EAP + IFAP + INSP)

\section{Conclusion}

Aroma of Assam aromatic rice collection may be due to $B A D H 2$ gene and with more than one allelic constitution. The phylogenic relationship indicates the ancestral origin of the aromatic rice may be of diverse. The present study also indicates probable presence of both indica and japonica type in Assam aromatic rice collection which needs further verifications.

\section{Acknowledgements}

The present work has been done as a part of project work funded by Department of Biotechnology, Govt of India .The authors acknowledge the same.

\section{Conflict of Interest}

Authors declare that they have no conflict of interest.

\section{Ethical Compliance Statement}

NA 


\section{Author's Contribution}

Conceptualization of research (SDD); Designing of the experiments (SDD); Contribution of experimental materials (SDD, DH); Execution of field/lab experiments and data collection $(\mathrm{DH})$

\section{References}

1. Botstein D, RL White, M Skolnick and RW Davis. 1980. Construction of a genetic linkage map in man using restriction fragment length polymorphisms. American Journal of Human Genetics 32, 314-331.

2. Bradbury LM, RJ Henry, Q Jin, RF Reinke and DL Waters L. 2005. A perfect marker for fragrance genotyping in rice. Molecular Breeding 16: 279-283 DOI 10.1007/s11032-005-0776-y

3. Buttery RG, LC Ling, BO Juliano and JG Turnbaugh . 1983. Cooked Rice aroma and 2-acetyl-1-pyrroline. Journal of Agricultural and Food Chemistry 31: 823-826.

4. Cordeiro GM, MJ Christopher, RJ Henry and RF Reinke. 2002. Identification of microsatellite markers for fragrance in rice by analysis of the rice genome sequence. Molecular Breeding 9: 245-250.

5. Dwivedi A, R Rathour, D Basandrai and AK Sarial. 2019. Molecular genetic diversity analysis using SSR markers of basmati rice (Oryza sativa L.) genotypes of northern hill region, India. Journal of Cereal Research 11(3): 224-230. http://doi.org/10.25174/22494065/2019/95583

6. Dudareva N, A Klempien, JK Muhlemann and I Kaplan. 2013. Biosynthesis, function and metabolic engineering of plant volatile organic compounds. New Phytologist 198:16-32. doi:10.1111/nph.12145

7. Fitzgerald TL, DLE Waters, LO Brooks and RJ Henry. 2010. Fragrance in rice (Oryza sativa) is associated with reduced yield under salt treatment. Environmental and Experimental Botany 68(3): 292-300.

8. Guide lines for the conduct of test for distinctiveness, uniformity and stability on rice (Oryza sativa L.) 2007 Plant Variety Journal of India. 1(1),

9. Hashemi FSG, MR Ismail, MY Rafii, F Aslani, G Miah, FM Muharam. 2018. Critical multifunctional role of the betaine aldehyde dehydrogenase gene in plants. Biotechnology $\mathbb{E}$ Biotechnological Equipment 32(4): 815-829.

10. Hinge VR, HB Patil and AB Nadaf. 2016. Aroma volatile analyses and $2 \mathrm{AP}$ characterization at various developmental stages in Basmati and Non-Basmati scented rice (Oryza sativa L.) cultivars. Rice 9: 38 https://doi.org/10.1186/s12284-016-0113-6

11. Islam M Z, M Khalequzzaman, M K Bashar, N A Ivy, MAK Mian, B R Pittendrigh, MM Haque and MP Ali. 2018. Variability assessment of aromatic rice germplasm by pheno-genomic traits and population structure analysis; Scientific Reports 8:9911 DOI:10.1038/s41598-018-28001-z

12. Jaccard P. 1908. Nouvellesrecherchessur la distribution florale, Bulletin de la Société vaudoise des sciences naturelles 44: 223-270

13. Jain S, RK Jain and SR Mc Couch. 2004. Genetic analysis of Indian aromatic and quality rice (Oryza sativa L.) germplasm using panels of fluorescentlylabeled microsatellite markers. Theoretical Applied Genetics 109: 965-977

14. Jin L, Y Lu, P Xiao, M Sun, H Corke and J Bao. 2010. Genetic diversity and population structure of a diverse set of rice germplasm for association mapping. Theoretical and Applied Genetics. 121(3): 475-87. doi: 10.1007/s00122-010-1324-7.

15. Kaur Y, R Kaur, R Khanna and N Sidhu. 2020. Assessment of genetic diversity in a set of rice (Oryza sativa $\mathrm{L}$ ) genotypes using molecular marker. Journal of Cereal Research 12(3): 327- 333. http://doi. org/10.25174/2582- 2675/2020/107380

16. Lorieux M, M Petrov, N Huang, E Guiderdoni and A Ghesquiere. 1996. Aroma in rice: Genetic analysis of a quantitative trait. Theoretical and Applied Genetics 93: $1145-1151$

17. Mahajan G, A Matloob, R Singh, VP Singh, BS Chauhan. 2018. Basmati rice in the Indian subcontinent: Strategies to boost production and quality traits. Advances in Agronomy 151: 159-213.

18. Mathure SV, N Jawali, RJ Thengane and AB Nadaf. 2014. Comparative quantitative analysis of headspace volatiles and their association with $B A D H 2$ marker in non-basmati scented, basmati and non-scented rice (Oryza sativa L.) cultivars of 
India. Food Chemistry 142: 383-391. doi:10.1016/j. foodchem.2013.07.066

19. Mathure SV, KV Wakte, N Jawali and AB Nadaf. 2011. Quantification of 2-Acetyl-1-pyrroline and other rice aroma volatiles among indian scented rice cultivars by HS-SPME/GC-FID. Food Anal Methods 4: 326-333. doi:10.1007/s12161-010-9171-3

20. Mo Z W, W Li, SG Pan, Fitzgerald TL, F Xiao, YJ Tang, YL Wang, MY Duan, H Tian and RX Tang. 2015. Shading during the grain filling period increases 2-acetyl-1-pyrroline content in fragrant rice. Rice. 8(1): 9 .

21. Sneath, PHA and RR Sokal. 1973. Numerical Taxonomy: The Principles and Practice of Numerical Classification. San Francisco: Freeman, 573pp.

22. Rohlf FJ. 1998, NTSYS-PC Numerical Taxonomy and Multivariate Analysis System, version 2.0, Exeter Software, Setauket, NY

23. Pachauri V, V Mishra, P Mishra, AK Singh, S Singh, R Singh and NK Singh. 2014. Identification of candidate genes for rice grain aroma by combining QTL mapping and transcriptome profiling approaches. Cereal Research Communication 42(3): 376-388.

24. Peng B, YH Zuo, YL Hao, J Peng, DY Kong, Y Peng, TY Nassiron, LL He, YF Sun, L Liu, RH Pang, YX Chen, JT Li, QY Zhou, B Duan, XH Song, SZ Song and HY Yuan. 2018. Studies on aroma gene and its application in rice genetics and breeding. Journal of Plant Studies 7(2): 29-41.

25. Prodhan Z H and SHU Qingyao2020 Rice Aroma: A Natural Gift Comes with Price and the Way Forward Rice Science. 27(2): 86-100

26. Roy S, A Banerjee, B Mawkhlieng, AK Misra, A Pattanayak, G D Harish, SK Singh, SV Ngachan and KC Bansal. 2015. Genetic diversity and population structure in aromatic and quality rice (Oryza sativa L.)
Grain morphology, molecular diversity and aroma analysis in rice

Landraces from North-Eastern India PLoS One. 10(6): e0129607. doi: 10.1371/journal.pone.0129607

27. Sood BC and EA Sidiq. 1978. A rapid technique for scent determination in rice. Indian Journal of Genetics Plant Breeding 38: 268-271.

28. Talukdar P R, S Rathi, K Pathak, S K Chetia and RN Sarma. Population structure and marker-trait association in indigenous aromatic rice. 2017. Rice Science 24(3): 145-154

29. Thakur D and DP Pandey. 2020. Genetic variability for yield and quality traits in local germplasm of rice of Himachal Pradesh. Journal of Cereal Research 12(2): 157-159. http://doi.org/10.25174/25822675/2020/'103761htt

30. Wakte K, R Zanan, V Hinge, Khandagale K, Nadaf A, Henry R. 2017. Thirty-three years of 2-acetyl-1pyrroline, a principal basmati aroma compound in scented rice (Oryza sativa L.): A status review. Journal of the Science of Food and Agriculture 97(2): 384-395

31. Widjaja R, JD Craske and M Wootton. 1996. Comparative studies on volatile components of non-fragrant and fragrant rices. Journal of the Science of Food and Agriculture 70: 151-161.

32. Wongpornchai S, T Sriseadka and S Choonvisase. 2003. Identification and quantitation of the rice aroma compound, 2-acetyl-1-pyrroline, in bread flowers (Vallaris glabra Ktze). Journal of Agricultural and Food Chemistry 51(2):457-462. doi:10.1021/jf025856x

33. Yi M, KT Nwe, A Vanavichit, W Chai-arree, T Toojinda. 2009. Marker assisted backcross breeding to improve cooking quality traits in Myanmar rice cultivar Manawthukha. Field Crops Research 113(2): 178-186.

34. Yoshihashi T. 2002. Quantitative analysis on 2-acetyl1-pyrroline of aromatic rice by stable isotope dilution method and model studies on its formation during cooking. Journal of Food Science 67: 619-622. 